\title{
LA PROHIBICIÓN UNIVERSAL DE LA TRATA DE PERSONAS
}

\section{THE UNIVERSAL PROHIBITION ON HUMAN TRAFFICKING \\ Luis-Carlos Amezúa ${ }^{1}$}

Recebido em: 15/04/2019 Aceito em: 17/07/2019 luiscarlos.amezua@uva.es
Resumo: El Derecho internacional prohíbe la trata de seres humanos y la moderna esclavitud, conceptos que incluyen la esclavitud estricta y otras modalidades de explotación como son el trabajo forzoso o la servidumbre, ya sea la servidumbre por deudas o el matrimonio forzoso. Todas estas conductas configuran la definición jurídica de trata de personas. En este artículo mostraremos cómo la situación actual ha hecho necesario expandir el concepto legal de esclavitud para castigar las formas contemporáneas de esclavitud, desarrolladas con la creciente precariedad en el ámbito de la economía globalizada. El TEDH y la CIDH están contribuyendo a configurar esa nueva etapa abolicionista.

Palavras-chave: Dignidad. Esclavitud Moderna. Servidumbre. Trabajo Esclavo. Trabajo Forzoso. Trata de Seres Humanos. Vulnerabilidad.

Abstract: International Law forbidden trafficking in human persons and modern slavery includes slavery and lesser types of human exploitation including: forced labour and servitudes, such as debt bondage or servile marriage, as set out in the established definition of trafficking in persons. All these modalities conform the legal definition on human trafficking. In this article we will show the current situation, which has made it necessary to expand the legal concept of slavery to punish contemporary forms of slavery, developed with increasing precariousness in the sphere of the globalized economy. ECHR and IACHR are helping to shape this new abolitionist era.

Keywords: Dignity. Modern Slavery. Servitude. Slave Labor. Forced Labour. Human Trafficking. Vulnerability.

\section{INTRODUÇÃO}

El delito de trata de seres humanos incluye en la actualidad toda una variedad de conductas coercitivas realizadas con la finalidad de conseguir la explotación laboral, servidumbre o esclavitud u otras conductas similares, explotación sexual, matrimonios concertados, mendicidad infantil o extracción de órganos.

En este artículo haremos una aproximación al fenómeno de la trata de personas con fines de explotación laboral para mostrar, en primer lugar, la hondura y extensión de esta grave violación de los derechos humanos. En segundo lugar, recogemos una síntesis de la normativa internacional concernida que está siendo utilizada por los tribunales para ir cercando esa realidad hasta hace poquito desconocida y que compromete a los Estados a desarrollar legislación y adoptar medidas eficaces en su ámbito competencial. En tercer lugar destacamos unas recientes sentencias de tribunales internacionales, en concreto del Tribunal europeo de derechos humanos y de la Corte interamericana de derechos humanos, como prueba de la cristalización jurídica de la llamada "nueva"

\footnotetext{
${ }^{1}$ Universidad de Valladolid - Valladolid - Espanha
} 
o "moderna esclavitud". Seguidamente podremos pasar a enunciar la tesis sobre la difícil erradicación de la trata y de las varias esclavitudes existentes, reconocidas o no, mientras persista el contexto de precariedad económica y laboral potenciado por la globalización de la economía. De ahí la hipótesis conclusiva de que los remedios paliativos actuales no pueden acabar con la explotación ni con la trata porque el sistema de la economía globalizada se alimenta de ellas, perpetúa la precariedad, invisibiliza la dominación, polariza a los débiles y los fragmenta, impidiendo la toma de conciencia de clase sometida. La solución vendrá, si acaso, de una transformación plena que contemple las relaciones entre personas, entre pueblos o entre Estados desde una óptica generosa de justicia distributiva global.

\section{LA MAGNITUD DE LA TRATA DE SERES HUMANOS}

En el ámbito de Naciones Unidas se ha tomado conciencia de la persistencia de la actualidad de modalidades de esclavitud como para que el Consejo de Derechos Humanos creara un organismo especializado que tiene el mandato de emitir informes anuales además de los informes de seguimiento a países concretos: una Relatora especial sobre las formas contemporáneas de la esclavitud, incluidas sus causas y consecuencias².

Ya en su Informe de 2016, la Relatora especial Urmila Bhoola, destacaba que la servidumbre por deudas era la principal forma de esclavitud contemporánea en todo el mundo ${ }^{3}$. En informes posteriores vuelve a reiterar los riesgos que está potenciando la economía globalizada y señala la propensión de las empresas transnacionales a favorecer estas "formas contemporáneas de esclavitud", al obtener productos o materias primas sobre todo en los niveles inferiores de suministro, en talleres pequeños $u$ hogares, donde se mueve una economía informal al margen de la legalidad y en condiciones que incluyen la esclavitud, el trabajo forzoso o la servidumbre por deudas ${ }^{4}$. Los estereotipos de género perpetúan situaciones de esclavitud o análogas en sectores económicos específicos, unos tradicionalmente feminizados y otros que afectan a hombres y niños ${ }^{5}$. La Relatora propone a los Estados que adopten un enfoque amplio basado en los derechos humanos para facilitar el acceso efectivo a la justicia y a vías de recurso.

En la actualidad se calcula que hay más de 40 millones de víctimas de la "moderna esclavitud", de las cuales alrededor de 25 millones sufren trabajo forzado y 15 han sido obligadas a

\footnotetext{
2 Pueden consultarse estos Informes a través de la Oficina del Alto Comisionado para los Derechos Humanos: <http://ap.ohchr.org/documents/dpage_s.aspx?m=160>.

${ }^{3}$ Informe de 4 de Julio de 2016 (A/HRC/33/46).

4 Informe de 2 de Agosto de 2017 (A/HRC/36/43), párrafo 38. Fue presentado al Consejo de Derechos Humanos ONU en su 36으 periodo de sesiones (11 a 29 de Septiembre de 2017). Disponible en: $\quad<h t t p s: / / d o c u m e n t s-d d s-$ ny.un.org/doc/UNDOC/GEN/G17/229/80/PDF/G1722980.pdf?OpenElement>. Ratifica estos datos en el Informe de 27 de Julio de 2018 (A/HRC/39/52), presentado al Consejo en su 39a periodo de sesiones (10 a 28 de Septiembre de 2018). Disponible en: <https://documents-ddsny.un.org/doc/UNDOC/GEN/G18/235/75/PDF/G1823575.pdf?OpenElement>.

5 Informe de 10 de julio de 2018 (A/73/139), presentado a la Asamblea General en su 73o periodo de sesiones.
} 
un matrimonio forzoso ${ }^{6}$. Los recientes datos actualizados en el Informe conjunto de la Organización Internacional del Trabajo, Walk Free Foundation y la Organización Internacional para las Migraciones, publicado el 19 de Septiembre de 2017 en el marco de la Asamblea General de Naciones Unidas, han dejado muy desfasados los anteriores de cinco años atrás (ILO 2012 Global estimate of forced labour $)^{7}$, al haberse contabilizado prácticamente casi el doble de personas que son víctimas de la moderna esclavitud. La recopilación de información tiene todavía que mejorar mucho, en especial en zonas de Asia central y los países árabes ${ }^{8}$.

De los veinticinco millones de personas atrapadas en el trabajo forzoso, unos 16 millones son explotadas en el sector privado, ya sea en el servicio doméstico, en el sector de la construcción o manufacturas y en faenas de pesca o agricultura, la mitad de ellas sujetas a servidumbre por deudas; unos 4,8 millones más son víctimas de explotación sexual forzosa y otros 4 millones están en situación de trabajo forzoso impuesto por el Estado.

La prevalencia de víctimas difiere entre las dos grandes categorías de esclavitud moderna, pues en Asia y el Pacífico hay 16,5 millones de personas sometidas a trabajo forzoso (4 por mil), mientras que en África prevalecen los matrimonios forzosos al cifrarse en 5,8 millones las personas afectadas (4,8 por mil).

En conjunto, las cifras globales de esta moderna esclavitud, agregando ambas conductas de trabajo forzoso y de matrimonios forzosos, resultan del siguiente modo en millones y según la tasa de prevalencia por cada mil habitantes de cada región mundial: África, con 9,2 millones (7,6 por mil), seguida de Asia y el Pacífico, con 24,9 millones (el 6,1 por mil), Europa y Asia central con 3,5 millones (el 3,9 por mil), América con 1,9 (el 1,9 por mil) y por fin, con datos escasamente fiables por falta de colaboración de las autoridades, los estados árabes con medio millón (3,3 por mil).

Estas nuevas estimaciones también muestran que las mujeres y las niñas se ven afectadas de manera desproporcionada por la esclavitud moderna, y representan casi 29 millones, o sea el $71 \%$ del total. Las mujeres representan el $99 \%$ de las víctimas del trabajo forzoso en la industria del sexo comercial y el $84 \%$ de los matrimonios forzados ${ }^{9}$. Además se estima que en los últimos cinco años, al

6 La OIT (ILO, por sus siglas en inglés) ha publicado el 19 de Septiembre de 2017 un informe actualizado con metodología innovadora basada en encuestas nacionales y tipología detallada sobre el perfil de las víctimas, modalidades, sectores, periodos y lugares de actividad, con datos recabados hasta el año 2016: Global estimates of modern slavery: Forced labour and forced marriage. Disponible en: <http://www.ilo.org/global/publications/books/WCMS_575540/lang--en/index.htm>. 7 Informe de la Relatora Especial sobre las formas contemporáneas de la esclavitud (A/HRC/33/46), § 10, p. 5. Los primeros datos se basaban en el ILO 2012 Global estimate of forced labour-Executive summary. Además reiterados en: Informe IV de la OIT (ILC.103/IV/1), reunión 2014, Anexo I, p. 93; Informe VI de la OIT (ILC.106/VI), reunión 2017, § 30-35, pp. 11-13. Estimaban el número de víctimas del trabajo forzoso en todo el mundo en torno a 20,9 millones de personas, de las cuales 5,5 eran niños. Esta información ha quedado ya superada con el posterior informe de 19/09/2017.

8 ILO Report, Global Estimates of Modern Slavery: Forced labour and forced marriage (Geneve, 2017), p. 6.

9 Los datos del ILO Report también pueden visualizarse, a través del Índice Global de Esclavitud realizado por la Fundación Walk Free, con leves diferencias respecto del oficial, pero con una presentación visual atractiva: <https://www.globalslaveryindex.org/>. 
menos 89 millones de personas en todo el mundo se han visto afectadas por alguna experiencia relacionada con estas modalidades de la moderna esclavitud durante periodos de tiempo que pueden transcurrir entre unos pocos días o llegar hasta los cinco años de sujeción.

La OIT también ha publicado una estimación complementaria del trabajo infantil ${ }^{10}$, en la que confirma que alrededor de 152 millones de niños, entre 5 y 17 años de edad, estaban sujetos a trabajo esclavo. La mayor parte está concentrada en tareas agrícolas $(70,9 \%)$ y el resto trabaja en el sector de servicios $(17,1 \%)$ y en la industria $(11,9 \%)$.

La importancia del fenómeno de la trata de seres humanos ha llevado a la comunidad internacional a integrar su erradicación en la Agenda 2030, como uno de los objetivos de desarrollo sostenible ${ }^{11}$. El Objetivo 8 pretende "promover el crecimiento económico sostenido, inclusivo y sostenible, el empleo pleno y productivo y el trabajo decente para todos", dentro del cual se indica como una de sus metas en séptimo lugar:

Adoptar medidas inmediatas y eficaces para erradicar el trabajo forzoso, poner fin a las formas modernas de esclavitud y la trata de seres humanos y asegurar la prohibición y eliminación de las peores formas de trabajo infantil, incluidos el reclutamiento y la utilización de niños soldados, y, a más tardar en 2025, poner fin al trabajo infantil en todas sus formas.

También en el ámbito de la Unión Europea fue establecida una Estrategia para la erradicación de la trata de seres humanos (2012-2016) ${ }^{12}$, que ha impulsado el desarrollo de la Directiva 2011/36/UE sobre prevención y lucha contra la trata y la protección de las víctimas. Cada país miembro, por su parte, desarrolla unos planes de lucha contra la trata que incluyen también modificaciones legislativas ${ }^{13}$. El artículo 5 de la Carta de los Derechos fundamentales de la UE prohíbe la esclavitud y el trabajo forzado ${ }^{14}$.

10 ILO Report, Global estimates of child labour. Results and trends, 2012-2016. Disponible en: <http://www.alliance87.org/global_estimates_of_child_labour-results_and_trends_2012-2016.pdf>.

11 Los 17 Objetivos de Desarrollo Sostenible (ODS) de la Agenda 2030 han entrado en vigor oficialmente el 1 de Enero de 2016. El documento oficial (http://www.un.org/es/comun/docs/?symbol=A/69/L.85) que implica un compromiso común y universal de los países fue adoptado por la Asamblea General de la ONU el 25 de septiembre de 2015 y este compromiso es la denominada Agenda 2030 para el Desarrollo Sostenible (A/69/L.85).

${ }^{12} \mathrm{COM} / 2012 / 0286$ final: <http://eur-lex.europa.eu/legalcontent/ES/ALL/?uri=CELEX\%3A52012DC0286>.

${ }^{13}$ Véase el Informe VI de la OIT (ILC.106/VI) para conocer el contexto jurídico y de políticas nacional, regional e internacional. Es un documento muy exhaustivo. Lleva por título:

"Principios y derechos fundamentales en el trabajo: Retos y oportunidades". Disponible en: <http://www.ilo.org/ilc/ILCSessions/106/reports/reports-to-theconference/WCMS_549969/lang--es/index.htm>. Además, tenemos una síntesis de los niveles de actuación concernidos en GARCÍA MEDINA, J., "La trata de seres humanos, una violación grave de derechos humanos", en REY MARTíNEZ, F. (dir.), Los derechos humanos en España: un balance crítico, Valencia, Tirant lo Blanch, 2015, pp. 815-846.

${ }^{14}$ La Carta (2016/C 202/02) fue proclamada solemnemente en Niza por el Parlamente Europeo el 7 de Diciembre de 2000 y vincula a los países miembros de la UE a partir de la entrada en vigor del Tratado de Lisboa, en Diciembre de 2009, con la misma validez jurídica que los tratados. Establece 


\section{NORMATIVA INTERNACIONAL}

Desde la abolición legal de la esclavitud en el siglo XIX, ha sido reiterada la prohibición de la misma en tratados y declaraciones internacionales como para no dejar duda de que la prohibición de la esclavitud forma parte del núcleo duro del ius cogens internacional.

Cuestión distinta es que la realidad contemporánea de las nuevas modalidades de explotación pueda merecer la calificación de crimen contra la humanidad y hacer aconsejable establecer instituciones de ámbito internacional para la persecución de esas conductas, como sería el dotar de atribuciones específicas a un tribunal penal internacional. Eso no parece conveniente ${ }^{15}$. En cambio, podrá tener más eficacia la participación activa de los Estados en la persecución de las conductas lesivas dentro de sus territorios, fomentando el establecimiento de reformas legislativas e institucionales, dotando de medios a tribunales y fuerzas de seguridad internas, para que se llegue a extirpar esta lacra persistente. La vía tomada desde comienzos de este siglo se orienta a impulsar la participación activa de los Estados, que son las instancias más directamente concernidas y en general mucho más adecuadas para perseguir los delitos que una instancia internacional infradotada, que en todo caso tendría que contar con la imprescindible ayuda de los Estados nacionales.

Además de la represión, se necesitan otras estrategias de carácter político e institucional, sobre todo preventivas y de promoción. Son medidas ineludibles, todavía desconocidas en la agenda política internacional, que presten atención a las causas de las migraciones, atajen la desigualdad mediante sistemas de protección social y procuren regular el reparto universal de un trabajo decente ${ }^{16}$.

Hasta tal punto han proliferado en esta última década los instrumentos jurídicos internacionales para la protección de las víctimas de la trata que podemos incluso considerar que estamos en una era "neo-abolicionista"17. Esto lo percibimos simplemente comprobando la multiplicidad de disposiciones, convenios internacionales, declaraciones o informes de distinto tipo que apoyan las motivaciones de resoluciones judiciales de carácter regional. Los tribunales nacionales e internacionales han aplicado normas cada vez más precisas y se pueden encontrar

en su artículo 5: "1. Nadie podrá ser sometido a esclavitud o servidumbre. 2. Nadie podrá ser constreñido a realizar un trabajo forzado u obligatorio. 3. Se prohíbe la trata de seres humanos".

15 VAN DER WILT, H., "Trafficking in human beings: A modern form of slavery or a transnational crime?", ACIL Research Paper, 2014-07.

${ }^{16}$ CASADEI, T., "Modos y formas de la esclavitud contemporánea", Derechos y libertades, 39 (2018), pp. 58-59.

17 Así lo califican dos reputados expertos: ALLAIN, J. y BALES, K., "Slavery and its definition", en ALLAIN, J. (ed.), The Law and Slavery. Prohibiting human exploitation, Boston-Leiden, Brill, 2015, cap. 22, pp. 502 y ss. Ya lo habían sostenido con anterioridad en el mismo trabajo, publicado por ejemplo en Global Dialogue, Vol. 14, Number 2 (summer/autumn 2012). Disponible en: $<$ http://ssrn.com/abstract=2123155>. Hay críticas muy serias sobre la ideología subyacente al nuevo abolicionismo y al pretendido final feliz, como recoge O'CONNELL DAVIDSON, J., Modern slavery. The margins of freedom, London, Palgrave, 2015, pp. 6-12 y passim. 
decisiones pioneras en el Tribunal penal Internacional ad hoc para la ex Yugoslavia, en el Tribunal Supremo de Australia, en la Corte Interamericana de Derechos Humanos y en otros tribunales ${ }^{18}$.

Aquí sólo me voy a referir a la normativa que utiliza como apoyo de sus decisiones el Tribunal Europeo de Derechos Humanos (TEDH) ${ }^{19}$, que no se caracteriza precisamente por haber mantenido una línea firme evolutiva en todas las ocasiones. Me referiré, no obstante, de modo escueto sobre la normativa que acredita este tribunal como fundamentación de la última sentencia importante que ha emitido hasta el momento. Este Alto tribunal utiliza en sus argumentos la doctrina asentada en decisiones anteriores, que van configurando progresivamente una doctrina acerca de la noción de vulnerabilidad y permitirán distinguir las muescas de erosión de la libertad personal y la degradación de la dignidad que es el trabajo esclavo. Más exhaustivo desde una perspectiva doctrinal, me parece relevante destacarlo, fue el desarrollo argumentativo de la sentencia Fazenda Brasil Verde en 2016, de la Corte interamericana de derechos humanos. En ella se explica con profusión la evolución de la protección jurídica frente a la esclavitud y sus variantes, tanto en el ámbito legal, como en el jurisprudencial y el doctrinal, que indicaremos más adelante.

El tribunal europeo se pronunció en una de las últimas sentencias sobre la afectación de la legislación europea e internacional que prohíbe la trata y la esclavitud, en el asunto Chowdury, de 30 de marzo de 2017. Esta sentencia recoge la normativa relevante ${ }^{20}$, y reenvía a los párrafos 49 a 51 de la sentencia Siliadin c. Francia (no 73316/01, CEDH 2005-VII) y a los apartados 137 a 174 de la sentencia Rantsev c. Chipre y Rusia (no 25965/04, CEDH 2010 -extractos), que explicitan las normas internacionales vigentes concernientes a las relaciones de trabajo forzoso, servidumbre, esclavitud y trata de seres humanos. Esta es la legislación internacional más directamente concernida, de conformidad con esa resolución judicial:

La Convención contra la esclavitud ${ }^{21}$, firmada en Ginebra el 25 de Septiembre de 1926; la Convención suplementaria sobre la abolición de la esclavitud, la trata de esclavos y las instituciones y prácticas análogas a la esclavitud ${ }^{22}$; el Convenio número 29 de la OIT $^{23}$; el Convenio sobre la

18 BEDMAR CARRILLO, E., "Concepción jurisprudencial de las formas contemporáneas de esclavitud", en PÉREZ ALONSO, E. (Dir.), El Derecho ante las formas contemporáneas de esclavitud, Valencia, Tirant lo Blanch, 2017, pp. 211-249; VALVERDE CANO, A.B., La protección jurídico-penal de las víctimas de las formas contemporáneas de esclavitud a la luz del Derecho internacional, europeo y nacional, Madrid, Editorial Centro de Estudios Ramón Areces, 2017.

${ }^{19}$ El TEDH fue constituido en 1959 en Estrasburgo por los Estados miembros del Consejo de Europa, para conocer sobre las demandas por vulneración del Convenio Europeo de Derechos Humanos, de 1950. La jurisprudencia es accesible desde la base de datos HUDOC (https://hudoc.echr.coe.int/eng\# )

20 Chowdury y otros c. Grecia, oㅜ 21884/15, CEDH 2017.

${ }^{21}$ La Convención sobre la esclavitud entró en vigor el 9 de Marzo de 1927:

<http://www.ohchr.org/SP/Professionallnterest/Pages/SlaveryConvention.aspx>. Puede accederse a la normativa en el ámbito universal a través de la web ONU en los Instrumentos Universales de los derechos humanos, agrupados en el apartado sobre esclavitud,

\section{servidumbre, trabajo forzoso e instituciones y prácticas análogas:}

$<$ http://www.ohchr.org/SP/Professionallnterest/Pages/UniversalHumanRightsInstruments.asp $x>$.

${ }^{22}$ Adoptada por una Conferencia de Plenipotenciarios convocada por el Consejo Económico y Social en su resolución 608 (XXI), de 30 de abril de 1956. Entró en vigor el 30 de Abril de 
abolición del trabajo forzoso (núm. 105), de la OIT24; el Convenio para la represión de la trata de personas y de la explotación de la prostitución ajena ${ }^{25}$; el denominado Protocolo de Palermo de Diciembre de 2000, que complementa la Convención de las Naciones Unidas contra la delincuencia organizada transnacional ${ }^{26}$. Además la sentencia Chowdury se remite al Convenio número 197 del Consejo de Europa sobre la lucha contra la trata de seres humanos ${ }^{27}$, del 16 de Mayo de 2005, así como los trabajos preparatorios del Consejo en la materia, recomendaciones del Parlamento y el informe explicativo: Recomendaciones de la Asamblea parlamentaria o 1523 (26 de Junio de 2001) y no 1623 (22 de Junio de 2004), que constatan oficialmente la revitalización de la esclavitud en Europa en forma de servidumbre doméstica²8; así como el Informe explicativo (STCE 197)29.

1957:

<http://www.ohchr.org/SP/Professionallnterest/Pages/SupplementaryConventionAbolitionOfS lavery.aspx>.

${ }^{23}$ El Convenio relativo al trabajo forzoso u obligatorio, fue adoptado en Ginebra en la 14 $4^{\text {a }}$ reunión de la Conferencia Internacional del Trabajo (28 de junio de 1930) y entró en vigor el 1 de Mayo de 1932:

<http://www.ilo.org/dyn/normlex/es/f?p=NORMLEXPUB:12100:0::NO:12100:P12100_INSTR UMENT_ID:312174:NO>. Normas del trabajo, lista de instrumentos, convenios y recomendaciones actualizados:

<http://www.ilo.org/dyn/normlex/es/f?p=NORMLEXPUB:12020:0::NO::.:>.

${ }^{24}$ Adoptado en Ginebra el 25 de Junio de 1957, entró en vigor el 17 de Enero de 1959: $<$ http://www.ilo.org/dyn/normlex/es/f?p=NORMLEXPUB:12100:0::NO::P12100_ILO_CODE:C 105>.

${ }^{25}$ Adoptado por la AG de Naciones Unidas en su resolución 317 (IV) de 2 de Diciembre de 1949. Entró en vigor el 25 de julio de 1951:

<http://www.ohchr.org/SP/Professionallnterest/Pages/TrafficlnPersons.aspx>.

\section{${ }^{26}$ El Portal "Human Trafficking Knowledge Portal"}

(https://www.unodc.org/cld/en/v3/htms/index.html) pretende facilitar la difusión de información sobre el cumplimiento de la Convención de las Naciones Unidas contra la delincuencia organizada transnacional y en especial cómo se va desenvolviendo el protocolo que la complementa, Ilamado de Palermo. Es el Protocolo para prevenir, reprimir y sancionar la trata de personas, especialmente mujeres y niños. Además ese Portal alberga enlaces a una base de datos legislativa y otra de jurisprudencia sobre casos de trata oficialmente documentados por los Estados miembros. La Convención contra la delincuencia fue aprobada en sesión plenaria de la Asamblea General (A/55/25) el 15 de Noviembre de 2000 y abierta a la firma en Palermo del 12 al 15 de Diciembre del mismo año. Tiene tres protocolos adicionales sobre tráfico de mujeres y niños, transporte ilícito y contrabando de migrantes y fabricación y comercio ilícito de armas de fuego.

${ }^{27}$ Hecho en Varsovia el 16 de Mayo de 2005, entró en vigor de forma general el 1 de Febrero de 2008.

${ }^{28}$ La primera Recomendación fue adoptada en la 18a sesión parlamentaria y muestra la alarma por la aparición de nuevo en Europa de la esclavitud doméstica 
El 9 de Noviembre de 2016 ha entrado en vigor el Protocolo de 2014 (núm. 29) relativo al Convenio sobre el Trabajo Forzoso, 1930 de la OIT, solamente ratificado hasta ahora por veintisiete países ${ }^{30}$, pero se está intentando ampliar el compromiso por defensores de los derechos humanos en todo el mundo y mediante la campaña "50 for Freedom" alentada por la OIT.

\section{LOS TRIBUNALES INTERNACIONALES}

\subsection{El Tribunal Europeo de Derechos Humanos (TEDH)}

EI TDHE ha tenido una trayectoria dubitativa para enfrentarse al problema de encajar las conductas de agresión a la dignidad entre las modalidades tipificadas en la legislación internacional ${ }^{31}$.

La primera vez que el tribunal europeo delimita el significado jurídico de "esclavitud" y "servidumbre" fue en el caso Siliadin contra Francia, de 26 de Julio de 2005. Para el Tribunal, ambas son conductas asimiladas, aunque se desglosen con el trabajo forzado en dos apartados del artículo 4.1 del Convenio Europeo de Derechos Humanos ${ }^{32}$. Como se remite a la Convención de 1926 sobre

(http://assembly.coe.int/nw/xml/XRef/Xref-XML2HTML-fr.asp?fileid=16924\&lang=fr), y la segunda Recomendación que fue discutida en la 19a sesión, constata que la mayoría de nuevas esclavas son mujeres inmigrantes, au-pair explotadas o esposas compradas por correspondencia

(http://assembly.coe.int/nw/xml/XRef/Xref-DocDetails-

FR.asp?FileID=17229\&lang=fr)

${ }^{29}$ Consejo de Europa (2005): Convenio del Consejo de Europa sobre la lucha contra la trata de seres humanos y su Informe Explicativo, Convenio núm. 197 de la Serie de Tratados del Consejo de Europa. <http://www.coe.int/fr/web/anti-human-trafficking >; $<\mathrm{http}: / / w w w . c o e . i n t / f r / w e b / c o n v e n t i o n s / f u l l-l i s t /-/ c o n v e n t i o n s / t r e a t y / 197>$. El Rapport explicatif del Convenio es accesible en la dirección: $<$ https://rm.coe.int/CoERMPublicCommonSearchServices/DisplayDCTMContent?documentl $d=09000016800 d 388 d>$.

30 Última consulta: 07/01/2019. Acceso a través de Normlex-Information System on International Labour Standars: <http://www.ilo.org/dyn/normlex/es/f?p=NORMLEXPUB:1:>.

${ }^{31}$ ANDRIANTSIMBAZOVINA, J., "L'esclavage, la servitude et le travail forcé ou obligatoire dans la jurisprudence de la Cour européenne des Droits de l'homme: une échelle pertinente des formes d'exploitation de l'être humain?", Droits, 52 (2010), pp. 97-120; FERNÁNDEZ BURGUEÑO, B., "EI trabajo forzado, la servidumbre y la esclavitud en Europa atendiendo a los sectores productivos: análisis crítico del alcance de la jurisprudencia del artículo 4 del Convenio europeo de derechos humanos", Universitas, 25 (2017), pp. 90-138.

32 El Convenio Europeo de Derechos Humanos, hecho en Roma el 4 de Noviembre de 1950. El artículo 4.1 de este CEDH dispone: “1. Nadie podrá ser sometido a esclavitud o servidumbre. 2. Nadie podrá ser constreñido a realizar trabajo forzado u obligatorio. 3. No se considera trabajo forzado u obligatorio en el sentido del presente artículo: a) Todo trabajo exigido normalmente a una persona privada de libertad en las condiciones previstas por el artículo 5 del presente convenio, o durante su libertad condicional. b) Todo servicio de carácter militar o, en el caso de objetores de conciencia en los países en que la objeción de conciencia sea reconocida como legítima, cualquier otro servicio sustitutivo del servicio militar obligatorio. c) Todo servicio exigido cuando alguna emergencia o calamidad 
la esclavitud y a la suplementaria de 1956, resulta de ello que el elemento definidor de esas conductas es la "cosificación", porque ahí en esta última su artículo 7.a define esclavitud como "el estado o condición de las personas sobre las que se ejercen todos o parte de los poderes atribuidos al derecho de propiedad, y esclavo es toda persona en tal estado o condición".

Es una aproximación reducida al fenómeno esclavista, aunque recoge la idea nuclear de erosión de la dignidad de la persona que está sometida a esclavitud ${ }^{33}$. Pero esta perspectiva nos aleja de la realidad porque presupone que ya no existen en el mundo regímenes jurídicos esclavistas sino que hallamos situaciones aisladas de sumisión menos onerosas, lo cual es, a mi juicio, desafortunado y desconoce la continuidad histórica entre las relaciones de esclavitud, otras relaciones contractuales de trabajo forzado temporal (engagement o indentured labour) y el trabajo asalariado dependiente, todas ellas dirigidas a la disciplinarización y fijación de la mano de obra laboral ${ }^{34}$.

El Protocolo de Palermo contiene la primera definición común que es jurídicamente vinculante a nivel internacional sobre el alcance de la noción de "trata de personas", su finalidad de explotación y las conductas incluidas como mínimo dentro de ella: la explotación de la prostitución ajena u otras formas de explotación sexual, los trabajos o servicios forzados, la esclavitud o las prácticas análogas a la esclavitud, la servidumbre o la extracción de órganos ${ }^{35}$. La trata se distingue del tráfico ilícito de migrantes, objeto de otro Protocolo complementario específico.

amenacen la vida o el bienestar de la comunidad. d) Todo trabajo o servicio que forme parte de las obligaciones cívicas normales".

${ }^{33}$ Un comentario elemental del CEDH puede consultarse en CANOSA USERA, R., "Prohibición de la esclavitud y del trabajo forzado: un ejemplo de integración entre tratados internacionales (Comentario al artículo 4)", en GARCÍA ROCA, J. y SANTOLAYA, P. (coords.), La Europa de los Derechos: el Convenio Europeo de Derechos Humanos, $2^{\underline{a}}$ ed., Madrid, CEPyC, 2009, pp. 145-162.

${ }^{34}$ Véase MOULIER-BOUTANG, Y., De la esclavitud al trabajo asalariado. Economía histórica del trabajo asalariado embridado, Madrid, Akal, 2006, pp. 223 ss. La idea reiterada en esta monumental obra del economista francés es el "embridamiento" de la movilidad.

35 Protocolo para prevenir, reprimir y sancionar la trata de personas, especialmente mujeres y niños, que complementa la Convención de las Naciones Unidas contra la Delincuencia Organizada Transnacional. El artículo 3 del Protocolo establece: "Para los fines del presente Protocolo: a) Por "trata de personas" se entenderá la captación, el transporte, el traslado, la acogida o la recepción de personas, recurriendo a la amenaza o al uso de la fuerza u otras formas de coacción, al rapto, al fraude, al engaño, al abuso de poder o de una situación de vulnerabilidad o a la concesión o recepción de pagos o beneficios para obtener el consentimiento de una persona que tenga autoridad sobre otra, con fines de explotación. Esa explotación incluirá, como mínimo, la explotación de la prostitución ajena u otras formas de explotación sexual, los trabajos o servicios forzados, la esclavitud - las prácticas análogas a la esclavitud, la servidumbre o la extracción de órganos; b) El consentimiento dado por la víctima de la trata de personas a toda forma de explotación intencional descrita en el apartado a) del presente artículo no se tendrá en cuenta cuando se haya recurrido a cualquiera de los medios enunciados en dicho apartado; c) La captación, el transporte, el traslado, la acogida o la recepción de un niño con fines de explotación se considerará "trata de personas" incluso cuando no se recurra a ninguno de los medios enunciados en el apartado a) del presente artículo; d) Por "niño" se entenderá toda persona menor de 18 años". 
La evolución de la sensibilidad y el avance en la comprensión de la esencia de la esclavitud han hecho posibles cambios legislativos y decisiones judiciales más abiertas. Sin embargo el TEDH ha sido más restrictivo recientemente que lo fuera en el caso Siliadin, y mucho menos receptivo a incorporar la doctrina elaborada por académicos en la motivación de sus decisiones, a diferencia de lo que hizo la Corte Interamericana en su decisión pionera de 20 de octubre de 2016, caso Trabajadores de la Hacienda Brasil Verde, en la que amplía el concepto de esclavitud en el sentido propuesto por las Directrices Bellagio-Harvard ${ }^{36}$.

Esta contención la apreciamos en la sentencia Chowdury y otros contra Grecia (no 21884/15), de 30 de marzo de 2017, a la que antes nos hemos referido. En ella el tribunal aprecia la vulneración del artículo 4 del Convenio europeo, estima por completo la demanda y condena a Grecia por falta de cumplimiento de sus obligaciones positivas, a saber, prevenir situaciones de trata de personas, proteger a las víctimas, investigar la denuncias con eficacia y castigar a los responsables de la trata.

La sentencia resuelve un asunto iniciado en 2013 que afectaba a varios inmigrantes bangladesíes que reclamaron la responsabilidad del Estado griego por el desamparo obtenido en los tribunales estatales donde denunciaron ser víctimas de trabajo forzoso y tráfico de seres humanos. Unos ciento veinte trabajadores inmigrantes sin permiso de residencia habían sido contratados para recoger fresas en un campo de Manolada, en el suroeste de Grecia (región de llia en el Peloponeso). Trabajaban jornadas agotadoras y no recibían la paga, incluso atrasada seis meses. En un momento en que reclamaron el salario recibieron disparos y treinta de los empleados fueron heridos, pero no todos denunciaron al tiempo, solo veintiuno de ellos presentaron la demanda. Sin embargo, el Tribunal de apelación de Patras absolvió a los tres capataces que dispararon y tampoco fue condenado el empresario, ni siquiera por haber empleado a inmigrantes indocumentados.

Precisamente el éxito económico alcanzado en esa región griega había sido exaltado por el primer ministro heleno, como motivo de orgullo después de la grave crisis económica que venía padeciendo la población griega y la necesidad que tuvo el país de acudir al apoyo internacional en 2010, aguantando las exigencias de la "troika" (Comisión Europea, Banco Central Europeo y Fondo Monetario Internacional) para sanear su economía. Esto manifiesta que ese modelo productivo tan apreciado ahí, como lo sigue siendo en otros lugares, se basa en la explotación de inmigrantes a quienes se mantiene en condiciones duras de alojamiento y de trabajo, con jornadas continuadas de doce horas en los invernaderos desde las 7 de la mañana a las 7 de la tarde, apenas un sueldo escaso que ni siquiera llegaban a cobrar; alojados en sitios insalubres, sin aseos ni agua corriente, en chamizos de cartón, nylon y bambú, estos trabajadores carecían de documentación, no tenían

\footnotetext{
${ }^{36}$ Estas Directrices (en inglés, Bellagio-Harvard Guidelines on the legal parameters of slavery) fueron adoptadas el 3 de Marzo de 2012 por un equipo de veinte investigadores y académicos que integraban el Research Network on the Legal Parameters of Slavery. Entre ellos figuran los siguientes: Jean Allain, Kevin Bales, Annie Bunting, John Cairms, William M. Carter Jr., Holly Cullen, Seymour Drescher, Stanley Engerman, Paul Finkelman, Bernard Freamon, Allison Gorsuch, Robin Hickey, Richard Helmholz, Antony Honoré, Aidan McQuade, Orlando Patterson, James Penner, Joel Quirk, Jody Sarich, Rebecca Scott. Pueden consultarse las Directrices en la web, o también en ALLAIN, J., "Property in persons: Prohibiting contemporary slavery as a human right. Appendix", en $\mathrm{XU}$, T. y ALLAIN, J. (eds.), Property and human rights in a global context, Oxford and Portland, Hart, 2015, pp. 113-119.
} 
permiso de residencia ni de trabajo, circunstancias todas ellas que podemos calificar como una situación de semiesclavitud.

En este caso el TEDH reitera doctrina jurisprudencial precedente para asentar la idea de que trabajo forzado evoca la idea de coacción física o moral ( $§ 90$, que remite a sentencias Van der Mussele c. Bélgica, de 23 de Noviembre de 1983, § 37; Siliadin § 117). La trata atenta contra la dignidad humana y los derechos fundamentales, siendo incompatible con una sociedad democrática y los valores de la Convención (§ 92, con apoyo en sentencia Rantsev, § 282). La explotación laboral es un aspecto intrínseco de la trata de seres humanos. La argumentación insiste especialmente en descartar que pueda considerarse de antemano la validez de prestación del consentimiento sin conocer todas las circunstancias de cada caso ( $\S \S 90,97$ y 98). Ello es así porque cuando un empleador abusa de su poder, humilla y amenaza a las víctimas y se aprovecha de la vulnerabilidad de sus obreros con el fin de explotarlos, estos no ofrecen sus servicios de manera voluntaria; incluso si al principio del acuerdo hubieran consentido, en el caso concreto analizado, esto cambió más tarde a causa del comportamiento de sus empleadores, pues los capataces los vigilaban con armas, los amenazaban y llegaron a disparar y herir gravemente a los trabajadores.

El Tribunal descarta que la situación de los demandantes equivaliera a una servidumbre, porque entiende como elemento fundamental que la distingue del trabajo forzoso que las víctimas tengan el sentimiento de que su condición de víctimas es inmutable y no susceptible de cambiar (§ 99, con referencia a la sentencia C.N. y V. contra Francia, § 91, no 67724/09, de 11 de Octubre de 2012). Lo que hubo fue un delito de trata de seres humanos y trabajo forzado, y ello -a diferencia de lo que entendió, equivocadamente, el tribunal de apelación de Patras (Grecia)- porque la restricción de movimientos no es una condición sine qua non para calificar una situación de trabajo forzoso o de trata. Puede haber una situación de trata a pesar de la libertad de movimientos.

A mi juicio, el Tribunal descarta la existencia de una situación de servidumbre, y todavía menos de esclavitud, no porque la más fácil calificación de los acontecimientos como situación de trabajo forzoso sea menos grave, sino precisamente para evitar el desamparo de las víctimas cuando se tiene todavía el prejuicio de que la esclavitud o las prácticas análogas a la esclavitud (estas son, en realidad, la servidumbre) exigen el ejercicio de un poder sobre las personas que evidencia el uso de atributos del derecho de propiedad.

Es el control sobre la persona lo que define el ilícito aprovechando la situación de vulnerabilidad y necesidad en que se encuentran las víctimas. El delito de trata de seres humanos, en efecto, comporta una limitación de la libertad de las víctimas; la compulsión física o la verbal y las amenazas no obedecen al exclusivo propósito de limitar la huida a las víctimas o la petición de auxilio, sino que forman parte de la más amplia conducta y propósito de someterlas a su criterio y dictados, a la semiesclavitud y servidumbre que solo con esas formas coactivas puede ofrecer resultados.

La capacidad de control sobre las acciones de las personas es elemento nuclear en la definición de la conducta delictiva y es normal que así sea porque la capacidad de disposición por uno mismo de su plan de vida es constitutivo esencial de la naturaleza humana frente a los determinismos biológicos y sociales. Parece, por lo tanto, el control y no tanto la libertad ambulatoria 
lo relevante, pues esta es emanación de la capacidad de control. Sin embargo, el TEDH no estimó que la violencia física, las amenazas y los disparos hechos por los guardianes, la jornada prolongada, la falta de remuneración, o la situación irregular de los inmigrantes en el país que dificultaba su escapada, fueran elementos para elevar la calificación jurídica del delito, valorando los hechos como una situación de servidumbre. Porque cabría haber entendido que los vigilantes estaban en posesión de la voluntad de las víctimas controlando su libertad, en el sentido de lo que las Directrices BellagioHarvard consideran como elemento constitutivo de los poderes concernientes al derecho de propiedad. El Tribunal se circunscribe a las categorías normativas asentadas sin quebrar su sentido jurídico con la penetración de interpretaciones doctrinales todavía no generalizadas.

Con posterioridad, el TEDH ha reafirmado que en materia de trata de seres humanos la legislación internacional rechaza la validez del consentimiento de la víctima para excusar el delito. Lo ha hecho en la sentencia S.M. contra Croacia, de 19 de Julio de 2018, que por primera vez aplica el art. 4 del Convenio europeo de derechos humanos (que prohíbe la esclavitud o servidumbre y trabajos forzados) a la trata y explotación de mujeres con fines de prostitución ${ }^{37}$. En este caso se aceptan como hechos probados que las autoridades estatales de Croacia atendieron la denuncia de la víctima, reconocieron el delito de trata y prestaron ayuda a la mujer denunciante, incluso apoyo psicológico y asistencia jurídica gratuita. Sin embargo, el TEDH estimó carencias en la investigación policial y judicial: las autoridades dejaron de interrogar a testigos relevantes, clientes y un amigo de la víctima; desconfiaron de la declaración de la víctima que decía sentirse amenazada por un hombre, antiguo policía y del que dependía económicamente; menospreciaron el trauma psicológico de la víctima, que afectaba a su manera de relatar su situación y por ello a su credibilidad (§§ 78-80). El consentimiento de la víctima es irrelevante ( $\$ 79$ in fine). Por todo ello, a pesar de la atención prestada por las autoridades estatales, condena a Croacia a indemnizar por daños morales.

\subsection{La Corte Interamericana de Derechos Humanos (CIDH)}

En el ámbito americano contamos con el pronunciamiento del tribunal internacional, que emite una sentencia muy bien fundamentada y rigurosa ${ }^{38}$. El 20 de Octubre de 2016 la Corte americana de San José de Costa Rica emitió una sentencia pionera que amplía la noción legal de esclavitud reinterpretando la añeja concepción romana de la misma como desempeño de potestades de dominio sobre cosas en un sentido innovador; y es más innovador aún porque incorpora al ámbito jurídico unas orientaciones promovidas desde las aportaciones de intelectuales, relacionando la esclavitud y un concepto de propiedad entendido como posesión del control para fines de explotación. La sentencia a que nos referimos resolvió el caso trabajadores de la Hacienda Brasil Verde contra Brasil, verificando la violación del artículo 6 de la Convención Americana sobre derechos humanos ${ }^{39}$.

\footnotetext{
37 S.M. contra Croacia, oㅜ 60561/14, CEDH 2018.

38 Corte IDH. Caso Trabajadores de la Hacienda Brasil Verde vs. Brasil. Sentencia de 20 de octubre de 2016. Serie C No. 318.

39 El artículo 6 de la Convención Americana de Derechos Humanos (Pacto de San José de Costa Rica, 22 de Noviembre de 1969) establece la prohibición de la esclavitud y servidumbre: "1. Nadie puede ser sometido a esclavitud o servidumbre, y tanto éstas, como la trata de esclavos y la trata de mujeres están prohibidas en todas sus formas. 2. Nadie debe ser constreñido a ejecutar un trabajo
} 
Concluye condenando a Brasil por violar las garantías laborales de 85 trabajadores que debieron ser rescatados de una hacienda en el estado de Pará, en el año 2000. Bástenos con esta sucinta información para hacernos una pequeña idea de algunos de los hechos probados de este complejo caso.

Los hechos conciernen a unos trabajadores que fueron reclutados por un intermediario (se le denomina "gato" en el lenguaje corriente y así lo recoge la sentencia) en el interior de Piauí. Después de varios días de viaje, cuando llegaron los trabajadores a la hacienda tuvieron que entregar su documentación y firmar contratos en blanco. Trabajaban jornadas agotadoras que duraban 12 horas o más, con apenas un descanso de media hora para almorzar y un día libre a la semana. Dormían bajo un techo de lona, en barracones sin electricidad, camas ni armarios. La alimentación era escasa, de pésima calidad y su precio era descontado del salario. Como consecuencia de ello, muchos de los jornaleros enfermaban habitualmente y ni siquiera recibían atención médica. Estaban constantemente amenazados y vigilados por guardias armados.

La sentencia se desarrolla con profusión en detalles de todo cariz. Es una sentencia muy extensa y doctrinalmente completísima, que hace un recorrido academicista por la evolución histórica de la regulación de la esclavitud hasta la actualidad en el marco del derecho internacional. Considera la esclavitud como una norma imperativa que impone obligaciones erga omnes. Constata que la definición legal de esclavitud no ha variado desde la Convención de 1926 contra la esclavitud, que define esclavitud en relación a la propiedad, por lo cual estaría reduciendo la noción jurídica de esclavitud a la que se ejercita sobre cosas o bienes muebles (la esclavitud tradicional o chattel slavery); y la Convención Suplementaria de 1956 se limitó a extender la protección contra la esclavitud también para "instituciones o prácticas análogas a la esclavitud". El Estatuto de Roma que crea el Tribunal Penal Internacional y la Comisión de Derecho Internacional agregaron a la noción jurídica de esclavitud el "ejercicio de los atributos de propiedad en el tráfico de personas".

Hechas esas constataciones y en relación con la prohibición de la esclavitud en el artículo 6 de la Convención Americana, la Corte IDH señala que el concepto ha evolucionado y ya no se restringe a la propiedad sobre la persona. Los elementos fundamentales para definir una situación como esclavitud son (§§ 269-271): el estado o condición de un individuo, que puede ser de iure o también de facto; y el ejercicio de alguno de los derechos de propiedad, comprendidos como posesión. En suma, que los dueños ejerzan poder o control sobre la persona esclavizada llegando a anular su personalidad.

forzoso u obligatorio. En los países donde ciertos delitos tengan señalada pena privativa de la libertad acompañada de trabajos forzosos, esta disposición no podrá ser interpretada en el sentido de que prohíbe el cumplimiento de dicha pena impuesta por juez o tribunal competente. El trabajo forzoso no debe afectar a la dignidad ni a la capacidad física e intelectual del recluido. 3. No constituyen trabajo forzoso u obligatorio, para los efectos de este artículo: a) los trabajos o servicios que se exijan normalmente de una persona recluida en cumplimiento de una sentencia o resolución formal dictada por la autoridad judicial competente. Tales trabajos o servicios deberán realizarse bajo la vigilancia y control de las autoridades públicas, y los individuos que los efectúen no serán puestos a disposición de particulares, compañías o personas jurídicas de carácter privado; b) el servicio militar y, en los países donde se admite exención por razones de conciencia, el servicio nacional que la ley establezca en lugar de aquél; c) el servicio impuesto en casos de peligro o calamidad que amenace la existencia o el bienestar de la comunidad, y d) el trabajo o servicio que forme parte de las obligaciones cívicas normales". 
Aquí está la clave, en la línea defendida por el profesor Jean Allain: el control requerido para calificar un acto como esclavitud equivale a una pérdida de la propia voluntad o una disminución considerable de la autonomía personal. Y continúa el tribunal precisando que ese "ejercicio de atributos de la propiedad" debe entenderse en los días actuales como el control ejercido sobre una persona que le restrinja o prive significativamente de su libertad individual, con intención de explotación mediante el uso, la gestión, el beneficio, la transferencia o el despojarse de una persona.

A continuación, la CIDH indica algunos de los elementos que reflejan los denominados "atributos del derecho de propiedad" (§ 272): restricción o control de la autonomía individual; pérdida o restricción de la libertad de movimientos de una persona; obtención de un provecho por el perpetrador; ausencia de consentimiento o su imposibilidad o irrelevancia; violencia física o psicológica; posición de vulnerabilidad de la víctima; detención o cautiverio; la explotación.

En el caso concreto, los hechos probados concluyen en la existencia de una situación de esclavitud (§ 304). La responsabilidad es del Estado de Brasil por incumplir su deber de garantía y no haber acreditado tomar las medidas que suprimieran la discriminación estructural histórica constada.

Estas someras consideraciones nos permiten mostrar el minucioso esfuerzo por adecuar los sistemas normativos a los cambios sociales. Los tribunales contribuyen no solamente a delimitar lo correcto de lo delictivo sino a educar a la sociedad. En este sentido, la dificultad de reconocer la esclavitud en conductas normalizadas es enorme en todos los países del mundo y no solamente en Brasil. Ahí la dificultad es obvia, porque existen realidades muy dispares en otras regiones del mismo país que afectan a emigrantes y a los mismos nacionales. En Brasil, el fenómeno del trabajo esclavo ha empezado a tener reconocimiento social entrado este siglo XXI, y todavía no es fácil que los propios afectados perciban la vulnerabilidad si no hay violencia física o encierro, porque la condición de miseria de la gente hace posibles relaciones de patronazgo que escapan a la regulación jurídica estandarizada ${ }^{40}$. Ello sucede, por ejemplo, cuando trabajadores de las haciendas desempeñan tareas sin horario ni control a cambio de ayudas eventuales del patrón, que aseguran el sustento de quien nada tiene ni a nada mejor puede aspirar que a recibir la gracia del amo si le regala un animal que haya rescatado, o le tolera cobijarse en sus terrenos, o cobra el pago de la zafra sin incluir riesgos de accidente o enfermedad. Esto, que es poco, es más que nada. $Y$ no se reconoce un trabajo como trabajo esclavo ni por la población del mismo entorno social ni por las instituciones, pues este tipo de tareas se han venido haciendo siempre así y lo normal es que la gente crea que esclavitud solo es aquella opresión tan grave como la padecida antiguamente en las plantaciones de caña o de algodón por los más indigentes y los negros. A esta ocultación de la verdad y legitimación de la esclavitud han contribuido los filmes holliwoodenses que han metido esas preconcepciones de violencia, barrotes, cadenas y castigos sanguinarios en nuestro imaginario, lo cual también repercute en la calificación jurídica de la explotación laboral por los propios tribunales ${ }^{41}$.

Por su parte, los defensores de los derechos humanos están contribuyendo a hacer visible la degradación de la vida de muchas personas. Los tribunales internacionales garantes de los derechos

40 LEÃO, L.H., "Trabalho escravo contemporâneo: a construção social de um problema público no Norte fluminense", Psicologia \& Sociedade, 27 (2015), pp. 125-127.

41 DIAS PAES, M.A., "L'histoire devant les tribunaux: la notion d'esclavage contemporain dans les décisions judiciaires brésiliennes", Brésil(s), 11 (2015), DOI: 10.4000/bresils.2172. 
humanos intentan encajar la realidad contemporánea a los tratados vigentes en el ámbito internacional, sin renunciar a incorporar aportaciones científicas procedentes de la sociología, de la historia o de la teoría jurídico-política que permitan soluciones imaginativas sin quebrar del todo las reglas que imponen criterios interpretativos en el ámbito internacional. No deja de ser una afectación del derecho por otros saberes que pueden erosionar a largo plazo la posibilidad de hacer acuerdos compartidos desde espacios culturales muy alejados. Convendría también recordar que la antigua URSS se opuso en su momento a incluir la abolición de las servidumbres en el núcleo de conductas prohibidas por la Convención Suplementaria de 1956, de modo que el compromiso diplomático llevó a referirse a las "prácticas análogas a la esclavitud" sustituyendo el concepto de "servidumbre" 42 . Y todavía más se complicaron los acuerdos con las polémicas descolonizadoras y sobre el apartheid en los años sesenta.

\section{CONTEXTO Y PROSPECTIVA}

La historiografía y los pensadores de formación marxista habían remarcado siempre la continuidad de situaciones de dominación para explotar el plusvalor. La creencia de que solo tenían aniquilada su dignidad los esclavos y que otros trabajadores dependientes eran libres, a pesar de que la autonomía real de ambos era la misma, ha sido tenazmente cultivada por las clases explotadoras. Esta es la opinión que sigue sosteniendo Orlando Patterson al referir que a mediados del XIX apenas tenían mejor situación los negros en régimen de esclavitud que los blancos pobres sometidos a penosas relaciones de trabajo; pero entonces se construyó la ideología de que los trabajadores de raza blanca eran superiores porque tenían libertad. Eran mejores por ser libres y blancos, aunque en la práctica realizaran tareas infrahumanas sin poder disponer de sí mismos, de su tiempo ni de llevar a cabo cambios en su existencia. Para Patterson lo que define la esclavitud es la ruptura del individuo con la sociedad a la que pertenece, la "muerte social" que impide su participación como miembro reconocido y apreciado ${ }^{43}$.

Esa aportación conecta con otros estudios históricos que enseñan las diversas modalidades de sujeción en la antigüedad análogas a la esclavitud ${ }^{44}$, y que también nos permite recuperar la idea de que no hay comportamientos aislados de explotación y erosión de la dignidad de la persona, sino que deben integrarse en el modelo productivo y en el contexto social en el que emergen las relaciones humanas. No hay comprensión aislada de una institución, la esclavitud, o de unas conductas de explotación, sino un sistema de relaciones socio-económicas que produce modalidades graduales de sometimiento. El fin es la extracción de beneficio y en momentos sirve para ello la esclavitud, en otros las relaciones semi-libres, en otros la precariedad.

42 ALLAIN, J., "125 Años de abolición: el derecho de la esclavitud y la explotación humana", en PÉREZ ALONSO, E. (Dir.), El Derecho ante las formas contemporáneas de esclavitud, Valencia, Tirant lo Blanch, 2017, pp. 164-168; ALLAIN, J., "Property in persons: Prohibiting contemporary slavery as a human right. Appendix", en XU, T. y ALLAIN, J. (eds.), op. cit., pp. 99-100.

43 PATTERSON, O., Slavery and social death. A comparative study, Cambridge, Harvard University Press, 1982.

${ }^{44}$ Por ejemplo, ARCHER, L. (ed.), Slavery and other forms of unfree labour, London and New York, Routledge, 1988. 
Todavía en nuestros días no acabamos de percibir con claridad la responsabilidad colectiva en la continuidad de estas modalidades de esclavitud y de trata. Hay una multiplicidad de conductas gradualmente aproximadas que están haciendo a quienes las padecen, cada vez más, rechazar a personas extranjeras o asiladas e inmigrantes que habitan con nosotros. Escondidos o invisibles, no se les quiere ver ${ }^{45}$. No se ha querido reconocer que la esclavitud ha continuado existiendo después de su abolición oficial, porque se relacionaba con su calificación legal asimilada al ejercicio de derechos de propiedad ${ }^{46}$. Tampoco ha facilitado el reconocimiento de esa realidad el desarrollo global de la economía que ha producido una avalancha de mercancías baratas en los países más desarrollados, sin que la gente se cuestionase en serio cómo eran producidas y a qué coste de sometimiento de los trabajadores. Las multinacionales se aprovechan y vulneran esos compromisos voluntarios de la llamada responsabilidad social empresarial ${ }^{47}$.

Pero en los inicios del siglo XXI se ha cobrado algo más de conciencia, o eso parece, al revelar que esa lacra de la esclavitud proseguía en otros continentes y que también existía en Occidente. No solamente la trata de personas con fines de explotación sexual, el tráfico de niños, sino también la reintroducción de la servidumbre doméstica y otras variedades de explotación laboral.

Ha habido una caída del bienestar y del empleo que está ocasionando una mengua acelerada de los derechos sociales ${ }^{48}$. Un elevado número de personas está en riesgo de caer en la marginalidad, porque no parece posible que se creen suficientes puestos de trabajo estable con salarios adecuados para millones de personas en todo el mundo, y ni siquiera en los países más desarrollados ${ }^{49}$. De ahí que Guy Standing sostenga que se está gestando una nueva clase global que

45 URRUTIKOETXEA BARRUTIA, M., "No se ve, no se toca y sin embargo, existe: la esclavitud hoy. Hacia una reconceptualización del trabajo esclavo", Lan Harremanak, 35 (2016-II), pp. 389-419.

${ }^{46}$ DELACAMPAGNE, C., História da escravatura, Lisboa, Texto \& Grafia, 2013, pp. 203-214. Para conocer otras modalidades de sometimiento que han pervivido siempre, véase BALES, K., Disposable people. New slavery in the global economy, Berkeley, University of California Press, 1999: casos de Tailandia, Mauritania, Brasil, Paquistán, India. Otras variantes de "engagés" persistieron en América tras las aboliciones y las tratas internas en África, como describen COQUERY-VIDROVITCH, C. y MESNARD, E., Ser esclavo en África y América entre los siglos XV y XIX, Madrid, Catarata, 2015, pp. 243-249 y 250-281.

47 RAIGRODSKI, D., "Creative capitalism and human trafficking: A business approach to eliminate forced labor and human trafficking from global supply chains", William \& Mary Business Law Review, vol. 8 (2016), pp. 71-134.

48 BELLOSO MARTíN, N., Os novos desafíos da cidadania, Santa Cruz do Sul, Edunisc, 2005, pp. 71-76.

$49 \mathrm{La}$ OIT informa de malas perspectivas para el empleo en el mundo. En sus proyecciones globales 2019-2020 prevé cerca de 190 millones de personas desempleadas en el mundo. En los años anteriores se confirmaron estos datos negativos: el Informe $\mathrm{VI}$ de la OIT (ILC.106/VI), § 6, p. 2: ralentización del crecimiento económico en las grandes economías emergentes o incluso una recesión en algunos países. El empleo vulnerable afecta a 1400 millones de personas en todo el mundo, con especial gravedad en las economías en desarrollo y emergentes. (Data Finder- 
denomina el "precariado"50. La situación de estos miembros de esa clase en gestación no es parangonable a la esclavitud estricta. Pero esas personas no serán libres por completo. A lo sumo semilibres, lo cual es tanto como decir semiesclavos. Creo que esto conforma una situación análoga a la esclavitud, unos escalones por debajo, que dificultará enfrentarse con decisión a la abolición de la esclavitud estricta. Si dispersamos los esfuerzos, los que se mueven en el filo de la pobreza, tendrán tanto miedo de caer en ella como para mostrarse por un lado sumisos, por otro, para ser pasto de consignas.

Esta percepción no es del todo nueva, pues ya en la transición del siglo XV al siglo XVII se produjeron cambios ideológicos para encubrir la realidad de la dominación, la miseria de los muchos y la riqueza de unos pocos, ocultando la injusta distribución de los medios de producción, la falta de trabajo decente y los salarios bajos. Entonces hubo una avalancha de escritos para minusvalorar a los pobres y de legislación para castigarlos, como si la pobreza fuera consecuencia de una moralidad personal perniciosa ${ }^{51}$. El objetivo consistía en asimilar a la población rural en un nuevo sistema que controlaba el tiempo de trabajo y requería interiorizar los nuevos valores de esfuerzo y ahorro. Se deseaba un sujeto que aceptase su baja condición como algo natural, esforzándose por salir adelante sin ayuda de nadie e identificándose con las normas de la cultura dominante.

La misma manipulación ideológica de las conciencias ha logrado implantarse en nuestros días en elites gobernantes y en la masa de población desde los centros difusores del neoliberalismo, que han conseguido una privatización de los riesgos por medio de aplicación de técnicas empresariales de gestión de las emociones. La repercusión mayor en la percepción social del trabajo y de la mala suerte del parado ha transformado la imagen del desempleo y la miseria como un reflejo de carencias personales imputables solo al que padece esa situación, culpabilizando a cada individuo por su holgazanería e irresponsabilidad ${ }^{52}$. Bajo la cobertura retórica del reconocimiento a nivel de principio de la autonomía personal y la concepción de que cada uno es dueño de su vida, sin embargo, los fracasos, la inseguridad o la pobreza serían, entonces, debidas solo a carencia de habilidades y actitudes individuales que, de ningún modo, concernirían a la estructura socioeconómica existente ni a los dirigentes globales que han provocado incertidumbres y la destrucción de comunidades básicas de apoyo.

Ante este panorama, ¿cómo pretender preocuparse -seriamente- de los demás oprimidos, cuando una mayoría degradada de la clase media hacia los márgenes siente que ha sido abandonada? La ruptura del contrato social entre las clases medias occidentales y las élites dominadoras hace posible cualquier evolución de los sistemas democráticos respetuosos con los derechos humanos hacia formas más autocráticas e insolidarias. Este fenómeno se extendiendo en

Tendencias 2019) Acceso: <https://www.ilo.org/global/research/global-reports/weso/2018/lang-es/index.htm>

${ }^{50}$ STANDING, G., El precariado. Una nueva clase social, Barcelona, Pasado y Presente, 2013.

51 GEREMEK, B., La estirpe de Caín. La imagen de los vagabundos y de los pobres en las literaturas europeas de los siglos XV al XVII, Madrid, Mondadori, 1991.

52 STANDING, G., El precariado, op. cit., pp. 83-84 y 211 ss. 
países emergentes y desarrollados que caen en manos de demagogos por el desencanto de la ciudanía o el resentimiento de la población que se considera marginada de las ventajas de la globalización.

Una hipótesis probable sería esta: no habrá apoyo verdadero para acabar con la nueva esclavitud porque la masa de precarios la desconoce o la desprecia y los privilegiados ni la ven o se benefician con su mantenimiento. Mientras persista este modelo neoliberal de organizar la sociedad con parámetros económicos extractivos, unos poquitos seguirán vampirizando a los demás. Y la gente que siga convencida de que debemos guiarnos por impulsos consumistas mantendrá su conformismo con la desigualdad volcando apenas la desazón en acciones compasivas, pero sin alterar radicalmente las condiciones que perpetúan la injusticia ${ }^{53}$.

Casadei y otros autores proponen reconfigurar una justicia distributiva que reconozca deberes positivos a escala global54. Pero si tuviera razón Thomas Nagel, el tránsito de los compromisos morales a los políticos necesita la previa configuración de instituciones globales dotadas de soberanía, por lo cual habría antes que padecer un periodo de injusticia global para que la reacción colectiva incentivara una reacción en pro de la legitimidad y de la justicia ${ }^{55}$.

\section{CONSIDERAÇÕES FINAIS}

El actual activismo internacional moviliza recursos dirigidos a la erradicación de la trata y de las "nuevas" modalidades de esclavitud; implica a múltiples actores, desde organizaciones no gubernamentales, agencias estatales que coordinan su intervención en la persecución de delitos, protocolos de actuación institucional, compromisos de desarrollo legislativo y una correlativa aproximación judicial que se fortalece con el diálogo entre tribunales y el apoyo mutuo de argumentos procedentes de instancias de países y regiones diferentes.

No obstante, el éxito previsto en la extinción práctica de la explotación no parece factible salvo un cambio radical del modo de vida promovido hoy en todo el mundo. La explotación de las personas no es ajena a los objetivos de crecimiento económico que orientan las decisiones políticas y económicas. Es imposible mantener el crecimiento sin esquilmar el planeta y por consiguiente, cualquier propuesta razonable de equilibrar el bienestar social y el cuidado de las personas, con la protección ambiental y la preservación de los recursos para generaciones venideras, tiene que pasar inevitablemente por la reducción del consumo desenfrenado. Hay que encontrar vías alternativas de subsistencia sin una producción exhaustiva que enriquece a muy pocos, bajo la apariencia de la

53 BAUMAN, Z., ¿La riqueza de unos pocos nos beneficia a todos?, Barcelona, Paidós, 2014, pp. 6971.

${ }^{54}$ CASADEI, T., "La 'nueva' esclavitud", Anales de la Cátedra Francisco Suárez, 43 (2009), p. 193; ARCOS, F., "Esclavitud contemporánea y justicia en un mundo globalizado", en ARCOS, F. (Ed.), La justicia y los derechos en un mundo globalizado. Madrid: Dykinson, 2015, pp. 75-92.

55 NAGEL, T., "The problem of global justice", Philosophy \& Public Affairs, 33 (2005), pp. 113-147. 
inevitabilidad de incrementar la producción de bienes fútiles para saciar los deseos consumistas fomentados entre la gente.

Sólo esa transformación ecológica profunda asumida colectivamente a escala global tendrá posibilidades efectivas de acabar con la actual explotación laboral y las otras variaciones de trata de seres humanos. Aun así, no es posible erradicar universalmente cualquier explotación sin tener en cuenta que la visión compasiva también proyecta un paternalismo prepotente sobre otros sujetos percibidos como víctimas, o acaso como inferiores. Tal vez la compasión bienintencionada que se traduce en perseguir unas determinadas variedades de trabajo "análogo a la esclavitud" llegue a ocultar que esas dependencias de sujetos miserables, gentes de otras razas, las mujeres pobres y los niños, podrían ser en realidad el intento de evadirse de sumisiones peores a la propia tribu, a la parentela o a la comunidad de origen, por decirlo así. Esas sumisiones seleccionadas por los activistas del abolicionismo, a decir de Julia O'Connell ${ }^{56}$, podrían preferirse de alguna manera, eligiendo ese sacrificio que llamamos semiesclavitud con la finalidad de alimentar a su familia y a otros menesterosos que dependan de su esfuerzo y lo prefieran para salir del círculo todavía más opresivo para ellos en que se había convertido su lugar nativo de procedencia.

La elección no es fácil si las opciones son (a) no tener nada para no ser explotado y (b) tener algo siendo uno sometido a explotación. Los casos extremos configuran hoy esas modalidades de trata de personas o la nueva esclavitud, pero también el precariado y tantos otros trabajadores eventuales están sometidos sin ser conscientes de ello a los vaivenes del destino y, sobre todo, a decisiones de actores escondidos dentro de un sistema productivo endiablado. La globalización ha exacerbado las tendencias explotadoras de los recursos naturales que caracterizan un tipo de sistema económico basado en el crecimiento permanente y ha acentuado también las necesidades de las personas, muchas veces reales y otras veces inducidas por la presión hacia el consumo. Hacen falta acuerdos internacionales que comprometan a los Estados y a los demás agentes globales, conciliando el respeto por la tierra con el bienestar de las personas y su dignidad. Para ello también debe mantenerse, hay que repetir de nuevo lo obvio, el respeto a las reglas del derecho y a los derechos humanos.

\section{REFERÊNCIAS}

ALLAIN, Jean. The law and the slavery. Prohibiting human Exploitation. Boston: Brill, 2015.

56 O'CONNELL DAVIDSON, J., Modern slavery. The margins of freedom, op. cit., pp. 186 y ss. 
ALLAIN, Jean. "Property in persons: Prohibiting contemporary slavery as a human right. Appendix", en XU, Ting \& ALLAIN, Jean (Eds.). Property and human rights in a global context. Oxford and Portland: Hart Publishing, 2015, pp. 93-119.

ALLAIN, Jean. "125 Años de abolición: el derecho de la esclavitud y la explotación humana". En PÉREZ ALONSO, E. (Director). EI Derecho ante las formas contemporáneas de esclavitud. Valencia: Tirant lo Blanch, 2017, pp. 147-182.

ALLAIN, Jean y BALES, Kevin. "Slavery and its definition". Global Dialogue, Vol. 14, N. 2, 2012.

ANDRIANTSIMBAZOVINA, Joël. "L'esclavage, la servitude et le travail forcé ou obligatoire dans la jurisprudence de la Cour européenne des Droits de l'homme: une échelle pertinente des formes d'exploitation de l'être humain?". Droits, París, N. 52, 2010, pp. 97-120.

ARCOS RAMÍREZ, Federico. "Esclavitud contemporánea y justicia en un mundo globalizado". En ARCOS, F. (Editor). La justicia y los derechos en un mundo globalizado. Madrid: Dykinson, 2015, pp. 75-92.

ARCHER, Léonie J. (Ed.). Slavery and other forms of unfree labour. London and New York: Routledge, 1988.

BALES, Kevin. Disposable people. New slavery in the global economy. Berkeley: University of California Press, 1999.

BAUMAN, Zygmunt. ¿La riqueza de unos pocos nos beneficia a todos? Barcelona: Paidós, 2014.

BEDMAR CARRILLO, Eulogio. "Concepción jurisprudencial de las formas contemporáneas de esclavitud", en PÉREZ ALONSO, E. (Dir.). El Derecho ante las formas contemporáneas de esclavitud. Valencia: Tirant lo Blanch, 2017, pp. 211-249.

BELLOSO MARTíN, Nuria. Os novos desafíos da cidadania. Santa Cruz do Sul: Edunisc, 2005.

CANOSA USERA, Raúl. "Prohibición de la esclavitud y del trabajo forzado: un ejemplo de integración entre tratados internacionales (Comentario al artículo 4)", en GARCÍA ROCA, J. y SANTOLAYA, P. (Coordinadores). La Europa de los Derechos: el Convenio Europeo de Derechos Humanos. $2^{\text {a }}$ edición. Madrid: Centro de Estudios Políticos y Constitucionales, 2009, pp. 145-162.

CASADEI, Thomas. "La 'nueva' esclavitud". Anales de la Cátedra Francisco Suárez. Granada, Vol. 43, 2009, pp. 167-194.

CASADEI, Thomas. "Modos y formas de la esclavitud contemporánea". Derechos y libertades. Madrid, № 39, 2018, pp. 35-61.

COQUERY-VIDROVITCH, Catherine y MESNARD, Éric. Ser esclavo en África y América entre los siglos XV y XIX. Madrid: Catarata, 2015.

DELACAMPAGNE, Christian. História da escravatura. Lisboa: Texto \& Grafia, 2013.

DIAS PAES, Mariana Armond. "L'histoire devant les tribunaux: la notion la notion d'esclavage contemporain dans les décisions judiciaires brésiliennes". Brésil(s). París, [En ligne], 11 (2015), DOI: 10.4000/bresils.2172.

FERNÁNDEZ BURGUEÑO, Borja. "EI trabajo forzado, la servidumbre y la esclavitud en Europa atendiendo a los sectores productivos: análisis crítico del alcance de la jurisprudencia del artículo 4 del Convenio europeo de derechos humanos". Universitas. Madrid. № 25, 2017, pp. 90-138.

GARCÍA MEDINA, Javier. "La trata de seres humanos, una violación grave de derechos humanos", en REY MARTÍNEZ, F. (dir.). Los derechos humanos en España: un balance crítico. Valencia: Tirant lo Blanch, 2015, pp. 815-846. 
GEREMEK, Bronislaw. La estirpe de Caín. La imagen de los vagabundos y de los pobres en las literaturas europeas de los siglos XV al XVII. Madrid: Mondadori, 1991.

ILO Report. Global estimates of modern slavery: Forced labour and forced marriage. Geneva: International Labour Organization, Walk Free Foundation and International Organization for Migration, 2017. Disponible en: <http://www.ilo.org/global/publications/books/WCMS_575479/lang-en/index.htm>. Acceso: 19/09/2017.

ILO Report. Global Estimates of Child Labour. Results and Trends, 2012-2016. Geneva: International Labour Organization (ILO), 2017.2 Disponible en: <http://www.alliance87.org/global_estimates_of_child_labour-results_and_trends_2012-2016.pdf>.

Acceso: 19/09/2017.

LEÃO, Luís Henrique da Costa. "Trabalho escravo contemporâneo: a construção social de um problema público no Norte fluminense". Psicologia \& Sociedade. Belo Horizonte, MG. Vol. 27 (2015), pp. 125-127.

MOULIER-BOUTANG, Yann. De la esclavitud al trabajo asalariado. Economía histórica del trabajo asalariado embridado. Madrid: Akal, 2006.

NAGEL, Thomas. "The problem of global justice". Philosophy \& Public Affairs. Vol. 33, № 2, 2005, pp. 113-147.

O'CONNELL DAVIDSON, Julia. Modern Slavery. The Margins of Freedom. London: Palgrave Macmillan, 2015.

ONU. Informe de la Relatora especial sobre las formas contemporáneas de la esclavitud, incluidas sus causas y consecuencias (A/HRC/39/52), del 27/07/2018. Acceso: http://ap.ohchr.org/documents/dpage_s.aspx?m=160

PATTERSON, Orlando. Slavery and social death. A comparative study. Cambridge: Harvard University Press, 1982.

RAIGRODSKI, Dana. "Creative capitalism and human trafficking: A business approach to eliminate forced labor and human trafficking from global supply chains". William \& Mary Business Law Review. Williamsburg, VA. Vol. 8, 2016, pp. 71-134.

STANDING, Guy. El precariado. Una nueva clase social. Barcelona: Pasado y Presente, 2013.

URRUTIKOETXEA BARRUTIA, Mikel. "No se ve, no se toca y sin embargo, existe: la esclavitud hoy. Hacia una reconceptualización del trabajo esclavo". Lan Harremanak. Revista de Relaciones Laborales. País Vasco. № 35, 2016-II, pp. 389-419.

VALVERDE CANO, Ana Belén. La protección jurídico-penal de las víctimas de las formas contemporáneas de esclavitud a la luz del Derecho internacional, europeo y nacional. Madrid: Editorial Centro de Estudios Ramón Areces, 2017.

VAN DER WILT, Harmen. "Trafficking in human beings: A modern form of slavery or a transnational crime?”. ACIL Research Paper. Amsterdam. № 2014-07.

\section{COMO CITAR ESSE DOCUMENTO:}

AMEZÚA, Luis-Carlos. LA PROHIBICIÓN UNIVERSAL DE LA TRATA DE PERSONAS. Revista do Direito, Santa Cruz do Sul, v. 1, n. 57, jul. 2019. ISSN 1982-9957. Disponível em: $<$ https://online.unisc.br/seer/index.php/direito/article/view/13450>. Acesso em: doi:https://doi.org/10.17058/rdunisc.v1i57.13450. 